\title{
Gender Stereotype in Toy Advertisements on Social Networking Sites
}

\section{Nor Jijidiana Azmi ${ }^{1}$}

(iD) 0000-0001-7922-7993

\author{
Isyaku Hassan ${ }^{{ }^{*}}$ \\ (iD) 0000-0002-8260-2894
}

Radzuwan Ab Rashid 1

(D) 0000-0002-1334-6268

\section{Zulkarnian Ahmad 2}

(iD) 0000-0002-3285-9413

\section{Nor Azira Aziz ${ }^{1}$}

(iD) 0000-0002-3662-8241

\section{Qaribu Yahaya Nasidi ${ }^{3}$}

(D) 0000-0003-3888-2945

\footnotetext{
${ }^{1}$ Faculty of Languages and Communication, Universiti Sultan Zainal Abidin, MALAYSIA

${ }^{2}$ Business School, Universiti Kuala Lumpur, MALAYSIA

${ }^{3}$ Department of Mass Communication, Ahmadu Bello Universiti Zaria, NIGERIA

*Corresponding author: isyaku87@gmail.com
}

Citation: Azmi, N. J., Hassan, I., Ab Rashid, R., Aziz, N. A., \& Nasidi, Q. Y. (2021). Gender Stereotype in Toy Advertisements on Social Networking Sites. Online Journal of Communication and Media Technologies, 11(4), e202122. https://doi.org/10.30935/ojcmt/11212

\section{ARTICLE INFO}

Received: 3 Mar 2021

Accepted: 20 Aug 2021

\begin{abstract}
Marketing and advertising messages are often designed to persuade and influence the consumers into purchasing the products or services usually designed based on market segmentation and target consumers. This segmentation may vary but the most common type of market segmentation is based on demographic information such as gender. In toy advertisements, children are the target markets. Research shows that most toy advertisements involve gender stereotypes. Therefore, this paper aims to explore the visual elements of gender stereotypes in children's toy advertisements on social media. Using a case study approach, children's toy advertisements on Mattel's official Facebook page were analyzed from January 2019 to December 2019. A total of 87 relevant advertisements were gathered and subjected to content analysis focusing on gender stereotype characteristics and the presence of boy(s) or girl(s) model(s) in the advertisements. The analysis was conducted based on gender stereotype characteristics and the presence of boy or girl models in the advertisement. The findings showed that advertisements for girl toys are more frequently posted on Mattel's official Facebook page than advertisements for boy toys. Further analysis revealed that the advertisements contained more feminine compared to masculine traits and role behaviors. However, a large majority of the advertised toys do not have emotional behaviors. It was envisaged that the findings of this study could advance our knowledge of gender stereotypes in toy advertisements.
\end{abstract}

Keywords: advertisement, gender, social media, stereotype, toys

\section{INTRODUCTION}

The advancement of technology has influenced the way corporations and marketers communicate with the audience. The utilization of the Internet helps the advertisers to interact with their target audience more 
effectively and efficiently using computer-mediated channels as the medium of communication (Boudreau \& Watson, 2006). Advertisements are often designed to persuade and influence consumers into purchasing the advertised products or services. An advertisement is defined as a paid form of communication that is used to disseminate information about products, services, or ideas using various means of communication to reach the audience (Bovée \& Arens, 1992). Considering the statement "information to reach the audience", O'Barr (2015) emphasizes that the advertisement must attract the consumer's attention so that it would lead to purchase intention.

Advertisements are designed based on market segmentation and the target consumers depending on the type of products or services. This market segmentation may vary but the most common type of segmentation is based on demographic information such as age, gender, and occupation. Children are among the common segmentation and there are many products and services targeted directly for children, such as dairy products, snacks, fast-food as well as low-nutrient food (Harris et al., 2020). According to Yildirim and Milla (2019), some corporations directly target their advertisement for children from an early age to develop the children's brand loyalty and preferences.

Apart from food products, toys are also among the products that are always associated with children. In toy advertisements, children are one of the common target markets. Although play-time is not necessarily involving toys, many toy companies utilize this opportunity to provide additional and significant materials for the children to enjoy their play-time activity. There are a wide variety of children's toys that exist in the market. The wide range of toys allows the children and their parents to choose the types of toy that suits their preferences and activities. Marketers provide not only advertising messages of the toys they offer but also, in some cases, persuade the parents and children by providing detailed information about the toys and their contribution toward the early development of children. In this regard, Gerbner et al. (1994) stated that children learn about toys through media as well as through their interactions with adults.

The advent of Social Networking Sites (SNSs) has changed how people consume news (Rashid et al., 2016; Hassan et al., 2020). SNSs refer to interactive media through which users build social networks or relationships with others, such as Facebook, Youtube, and Twitter (Baek, 2015; Boyd et al., 2007; Obar \& Wildman, 2015). Toy advertisements in online platforms often represent gender-based behavioral codes that are related to the target consumers, where toys are categorized based on gender (Auster \& Mansbach, 2012). The characterization of gender can be observed in many aspects including the content of advertisements. However, the content is of great concern as researchers believe that most toy advertisements targeted to children involve gender stereotypes (Kane, 2006; Kahlenberg \& Hein, 2010; Owen \& Padron, 2015; Zimmermann, 2017).

Recent studies have examined gender stereotypes in advertisements (e.g., Davis \& Hines, 2020; Fine \& Rush, 2018). However, very few studies focused specifically on gender stereotypes in SNS advertisements (Auster \& Mansbach, 2012). Thus, this study aims to explore the visual elements of gender stereotypes in toy advertisements, particularly on Mattel's Facebook page, from the hypothetical perspective of Gender Schema theory. This theory explains how children understand gender roles as well as the consequences of gender stereotypes (Bem, 1981; Canevello, 2020). To the best of our knowledge, none of the previous studies focused on Mattel's Facebook page. This fact serves to highlight the relevance of the present study. To achieve the objectives of this study, we conducted a content analysis of the visual elements of toy advertisements based on traits, emotions, and role behaviors in the advertisements. Altogether, 87 children's toy advertisements that were advertised from January 2019 to December 2019 were chosen as the unit of analysis of this study.

\section{About Mattel}

Mattel was founded in 1945 as Ruth, Elliot Handler, and Harold Matt Matson launched a new company named "Mattel", out of a garage workshop in Southern California. The first Mattel's products are picture frames, but Elliot developed the side business of house-dolls furniture made from house frame scraps. Encouraged by the success of the doll furniture, the Handlers turned the company to toys manufacturing. Barbie leads Mattel to the forefront toy industry (Timeline, n.d.).

The company portfolio of brands and products include Mattel Girls and Boys Brands, including Barbie fashion dolls and accessories, Polly Pocket, Little Mommy, Disney Classics and Monster High, Hot Wheels, 
Matchbox, and Tyco R/C vehicles and playsets, and CARS, Radica, Toy Story, Max Steel, WWE Wrestling, ND Batman, and games and puzzles; Fisher-Price Brands, and American Girl Brands. Mattel provides a broad range of toys which made the company one of the largest toy industries in the world aside from Hasbro.

Both Hasbro and Mattel struggled with the loss of Toys R Us in 2018. According to market researcher NPD Group, industry-wide sales of toys dropped by two percent in 2018 (cnbc.com, 2019). Although the stock is down nearly six percent over the past year, putting its market value at $\$ 4.3$ billion. Mattel soars as the company exceeded analyst expectations during the fourth quarter of 2018. Mattel has won the round over Hasbro as Hasbro posted weaker than expected profits and continued to blame Toys Around Us for its sales woes. Mattel continues to lead the toy industry with four prestigious "Toys of the Year" awards at the 2020 Toy Association's annual awards ceremony (news.mattel.com).

As a toy company, children are Mattel's main target audience. Children all over the world, from different backgrounds, spend much of their time playing. This is a common activity for children as The United Nations High Commission for Human Rights (1989) declared that play should be a basic right for all children. Piaget (1964) also claims that play offers children opportunities to demonstrate their semiotic and cognitive abilities. Initially, playing is crucial for the children's social and emotional development, creativity, as well as language skills.

\section{Advertisement on Social Networking Sites}

Although the SNS advertisement is considered a relatively new research area (Knoll, 2016), some studies have been conducted in this field (e.g., Li, 2011; Dao et al., 2014; Saxena \& Khanna 2013; Tan et al., 2018; Sinha \& Singh, 2020; Sadek, 2021). Most of these studies established that SNSs have received great recognition as a means of product advertisements. The acceptance of SNS advertisements "was further facilitated by positive peer influence and congruity between a user's self and an advertised brand" (Knoll, 2016, p. 15). Also, SNS advertisement is relatively cheaper compared to traditional advertisements (Tan et al., 2018). In essence, most advertisers have allocated huge amounts of their budgets to SNS advertisements (Li, 2011; Saxena \& Khanna, 2013).

Research shows that SNS users view advertisements that are informative and entertaining as more valuable (Dao et al., 2014; Saxena \& Khanna, 2013). This increased value leads to higher buying intentions of advertised products (Dao et al., 2014). Accordingly, Sadek (2021) found that clear information, entertainment, trustworthiness, and creativity are crucial elements of effective SNS advertisements. Besides, various techniques are used in SNS advertisements to persuade buyers. In this regard, Tan et al. (2018) identified the most popular advertising techniques among 250 YouTube videos. The study found that taste appeal, uniqueness, novelty, animation, fun appeal, promotional characters, price, and health and nutrition benefits were most commonly used. There is evidence that, with the advancement of SNSs, advertising becomes more effective and efficient than ever before (Antoniadis et al., 2019; Walter \& Gioglio, 2014). This development has changed the landscape of communication and how consumers think and behave (Antoniadis et al., 2019; Mir \& Zaheer, 2012; Sinha \& Singh, 2020).

SNS advertisements contain important key features such as attention and mutuality. The platform also has additional features that allow two ways of communication and it is more interactive compared to other types of communication media. Interactivity is a core feature of internet advertisement (Kim \& McMillan, 2008). This unique feature allows companies to share and exchange information with customers about their products or services (Ohajionu \& Mathews, 2015). Today's SNS technology has shifted the way people and brands tell their stories by altering communication patterns and allowing messages to reach billions of users across the globe (Friedman, 2017; Lopez-Castroman, et al., 2020). This scenario has also changed the way advertising activities are run by companies (Gallaugher \& Ransbotham, 2010; Sinha \& Singh, 2020).

Apart from product and service advertisements, SNSs also enable companies to build a strong rapport with their customers (Antoniadis et al., 2019; Mangold \& Faulds, 2009). This feature benefits the companies in many economic and social aspects as it allows more audiences to respond to the advertisements (Kotler, 2002). Additionally, the ability of the companies to analyze their target audience and their demographic characteristics helps the companies to identify the most suitable SNS platform that can be used to successfully market their products (Chernova et al., 2018). A positive impact of SNSs is that it allows the corporations to 
directly create, initiate, circulate, and distribute information to consumers about particular products, brands, or services.

Although the conventional media, particularly television and newspapers, have been widely used as a major platform to advertise products and influence the audience's purchase intention and decision (Bansal \& Gupta, 2014; Chan \& Chan, 2005; Neto \& Furnham, 2005), they have reasonably higher advertising costs compared to SNSs (Tan et al., 2018). Thus, SNSs become crucial to advertisers as they market and promote a variety of products and services at low cost. Moreover, corporations can choose a wide range of SNSs to create advertising messages. This scenario has influenced consumers' behavior, purchase intention, information acquisition, and brand preferences (Mangold \& Faulds, 2009). Besides, consumers can easily obtain information regarding the product or service via SNSs by just clicking on the link provided by the marketers.

Today, many corporations use SNSs to advertise and market their products and services. Mattel, one of the most well-known toy companies in the world, also utilizes SNSs to advertise toy products. To date, Mattel has more than 1000 advertisement posts on its Facebook page that are designed to provide information about new or existing toys produced by the company.

\section{Gender Stereotype in Toy Advertisements}

Gender can be understood as a social process that organizes human beings into two categories: masculinity and femininity. Killerman (2013) gives a simple definition of gender as socially constructed behavior that society expects and considers most appropriate for men and women based on their biological characteristics. The differences between masculine and feminine characteristics can be observed in many aspects of human life such as professions, sports, daily routine, behavior as well as physical and cognitive traits (Blakemore et al., 2009; Owan et al., 2020) which occur in various stages of life. These differences can also be observed in children's preferences when it comes to choosing toys. Hines (2015) noted that boys and girls play with different types of toys and they also have different styles of play. Most of the toys that are available in the market have different characteristics classified based on gender (Alexander \& Hines, 2002). Toys that are targeted to boys usually include sports equipment, vehicles, and superhero characters while toys that are targeted to girls normally have feminine characteristics such as fashion dolls, princess paraphernalia, and kitchen or domestic role play (Blakemore \& Centers, 2005).

A number of studies were conducted to examine gender stereotype in advertisements (e.g., Auster \& Mansbach, 2012; Davis \& Hines, 2020; Fine \& Rush, 2018; Hoy \& Milne, 2010; Kahlenberg \& Hein, 2010; Owen \& Padron, 2015; Samuelson, 2021). These studies emphasized the existence of gender stereotypes in toy advertisements, particularly through manipulations of design features. For instance, Kahlenberg and Hein (2010) conducted a content analysis to examine gender stereotypes in 455 toy advertisements based on types of toy, gender portrayal, gender orientation, age of children, type of interaction, as well as setting and color of setting. The findings revealed that there were more girls than boys in the advertisements. The characters played indoor and in mixed-colored settings. According to the study, boys were more likely to be shown outdoors.

Additionally, Owen and Padron (2015) analyzed action figures advertised for girls and those advertised for boys to identify a gendered language. According to the findings, female action figures were portrayed as emotional and social, while male action figures represented stereotypic masculinity and aggression. Additionally, Zimmermann (2017) relied on interviews to examine gender classification and commercial preferences among 60 preschool children in the US. The study found that there is stereotype flexibility and rigidity in the classification and preferences while adherence to stereotypes was more prominent in boys and increased with age. According to there is a "continuous trend of unequal representation in advertisements" (Samuelson, 2021, p. 6). Thus, gender stereotypes in advertisements could lead to a distorted perception of gender roles in society (Carta et al., 2021).

Moreover, Hoy and Milne (2010) determined gender differences in advertisement among 589 young adult Facebook users. According to the study, only half of the participants were conscious of how their personal information is used for advertisement. Also, female users were more conscious of their privacy than male users. Similarly, a systematic review and meta-analysis conducted by Davis and Hines (2020) show that boys preferred boy-related toys more than girls did, and girls preferred girl-related toys more than boys did. Girls 
also preferred toys classified as neutral more than boys did, and gender-related differences increased with age. Fine and Rush (2018) found that gendered toy marketing misrepresents the overlapping and flexible toy interests of boys and girls in male-typed and female-typed toys as distinct and fixed while advertisements increase stereotype-consistent toy preferences and reinforce gender stereotypes. Davis and Hines (2020) also mentioned that there are gender-related differences in children's toy preferences, but the extent of these differences has not been proven.

Children's preference in choosing the toys may be influenced by a few factors such as explicit verbal labeling or implicit verbal labeling (Weisgram et al., 2014). Besides, children select toys based on visual preferences (Alenxander et al., 2009). In this regard, Pike and Jennings (2005) stated that toy advertisements have significantly influenced children's perceptions of choosing the appropriate toys for boys or girls. On the other hand, Leaper and Friedman (2007) stated that socializing agents such as parents and peers influence the children's choice of toys.

To sum up, previous research has explored gender stereotype indicators in toy advertisements such as colors, names, logos, language, and preferences. Toys often reflect stereotypes through manipulations of design features that signify toy play gender appropriateness. Toy companies tend to overstate gender differences when advertising toy products (Auster \& Mansbach, 2012; Bakir et al., 2008). Very few studies focused specifically on toy advertisements on SNSs. For instance, Auster and Mansbach (2012) examined the extent to which toys for boys and girls share characteristics based on color and type of toys on a popular website. The study hypothesized that the color palette of toys would reflect gender stereotypes. According to the study, bold colored toys such as red, black, and brown, as well as action figures represent toys for boys, while pastel colored toys such as pink, purple toys, as well as dolls represented toys for girls.

\section{Theoretical Approach}

This study is based on the Gender Schema theory developed by Sandra Bem during the 1980s. This theory presumes that through their interaction with people and the media, children begin to develop gender schemas once they notice that individuals are organized into male and female categories (Bem, 1981). These schemas enable children to generate and organize information as well as recognize toys that are appropriate for each gender. Gender schemas are categorized into two groups: In-group schemas, which represent the group to which a person belongs; and out-group schemas, which represent the opposite group (Canevello, 2020). As soon as children recognize their in-group, they begin to overlook any information that does not suit their in-group schema. This situation suggests that gender schemas have a strong influence on children's perceptions of the world (Martin \& Halverson, 1981).

Additionally, Gender Schema theory explains the implications of gender stereotypes and how children form and understand gender roles and characteristics, including "preferences, skills, personality traits, behaviors, and self-concepts" (Canevello, 2020, p. 1741). Gender Schema theory has been applied to study gender stereotypes in different areas, such as video games (Beasley \& Collins Standley, 2002) as well as social media and online advertisements (Crowe, 2015; Van Oosten et al., 2017). Specifically, Gender Schema theory predicts that children's "gendered behavior can reinforce gender role orientations" (Crowe, 2015, p. 151). A such, children may form their perceptions of gender roles based on how they are "confronted with media messages about gender stereotypes from a young age" (p. 159). Likewise, such reinforcement may occur for children's consideration of gender roles in toy advertisements on SNSs. Based on this central theoretical principle, this study explores gender stereotypes in toy advertisements on Mattel's Office Facebook Page.

\section{METHODOLOGY}

Using a case study approach, Mattel's Official Facebook Page was observed from January 2019 to December 2019. Relevant advertisements were chosen based on purposive sampling where the advertisements need to have visual representations of toys and roles of gender. A total of 87 advertisements were gathered and subjected to content analysis. Rudy et al. (2010) described several motivations for conducting research using content analysis which could be aligned with the present study. These motivations include studying gender-based inequalities as well as the effects that "message producers have on message 
content" and that which "message has on the audience". Similarly, this type of content analysis has been used by Auster and Mansbach (2012) on the color and types of toys featured on the Disney Store Website.

Auster and Mansbach (2012) claimed that their examination of the gendered marketing of toys on the Internet reflects the impact that message producers have on message content although their study failed to determine the actual effect of content on the audience, namely those purchasing the toys. Therefore, the present study incorporates content analysis to explore the visual representations of gender in toy commercials. This is because content analysis allows for the quantification of visual elements, including videos (Bock et al., 2011; Hassan \& Azmi, 2019), as well as advertisement features (Meyer et al., 2019; Schimmelpfennig, 2019). According to Weaver (2007), this content analysis is considered a robust research method based on facts.

\section{Coding Procedure}

At the initial step of data coding, all relevant advertisements were collected, and subsequently, datasets were generated. Each advertisement was considered and coded using hierarchical coding. A hierarchical code system represents a huge amount of information in a rather small number of digits (Hsieh \& Shannon, 2005). The coding characteristics comprised: 1) Toys' color, which was categorized into several colors such as blue, black, white, pink, purple, etc; 2) toy straits, which was classified into male, female or neutral character; 3) role behavior, which as categorized into masculine, feminine, or neutral; 4) and emotions, consisting of masculine emotion, feminine emotion, or neutral emotion.

\section{Reliability and Data Analysis}

The researchers carefully coded the advertisement data based on the coding characteristics explained in the previous section. This process involves subjective judgment, but inter-coder reliability can help to achieve reliable and quantifiable results (Creswell, 2003). To ensure credibility, inter-coder reliability was performed with the aid of a second coder. Afterward, the level of inter-coder agreement was ascertained using Cohen's kappa test. The inter-coder reliability results revealed $100 \%$ agreement with regards to toys' color, toy traits, and role behavior except for toys' emotions which has a Cohen's kappa agreement of .893. Cohen's kappa reliability has been recognized in providing robust data for content analysis (Cohen et al., 2007; Hassan et al., 2017). Subsequently, the researchers performed a descriptive statistics analysis to ascertain the distributions of categorical variables for toys' color, toy traits, role behavior, and toys' emotions via the Statistical Package for Social Sciences (SPSS) (SPSS Inc., Chicago, IL, USA, 20.0).

\section{FINDINGS}

A total of 87 toy advertisements on Mattel's official Facebook page were analyzed. In comparison, advertisements for girl toys are more frequently posted on Mattel's official Facebook Page compared to advertisements for boy toys. The findings of this study are presented based on the portrayal of gender in toy advertisements and the characteristics of gender stereotypes. The following sections provide a detailed presentation and discussion on gender stereotypes in children's toy advertisements on Mattel's official Facebook.

\section{Portrayal of Gender in Toy Advertisements}

The portrayal of gender in toy advertisements on Mattel's official Facebook was studied from the type of toys featured in the advertisements. These findings are depicted in Table 1.

As shown in Table 1, 40 out of 87 toys advertised on Mattel's official Facebook, which amounts to $45.9 \%$, are targeted to girls. For instance, toys such as dolls, accessories, and magical animals are targeted to girls because these toy advertisements featured girl models playing with particular toys. The findings also show that the most dominant color palettes portrayed on Mattel's Facebook toy advertisements are pink, purple, and blue. The toy advertisements targeted to girls apply more feminine and soft colors such as pastel pink that is combined with white or purple as the theme color for the advertisements. Besides, the advertisements targeted to girls also have other effects such as sparkly and glittery. 
Table 1. Frequency of toy advertisements based on gender

\begin{tabular}{lcc}
\hline Gender & Frequency $(n)$ & Percentage (\%) \\
\hline Male & 32 & 36.8 \\
Female & 40 & 45.9 \\
Neutral & 15 & 17.3 \\
\hline Total & $n=87$ & 100 \\
\hline
\end{tabular}

Table 2. Frequency of gender stereotypes in toy advertisements

\begin{tabular}{lcccccc}
$\begin{array}{l}\text { Type of gender } \\
\text { stereotype }\end{array}$ & $\begin{array}{c}\text { Agency associated with } \\
\text { male }\end{array}$ & \multicolumn{2}{c}{$\begin{array}{c}\text { Communality -Associated with } \\
\text { Female }\end{array}$} & $\begin{array}{c}\text { Neutral - Associated with both } \\
\text { gender }\end{array}$ \\
\hline & $\begin{array}{c}\text { Frequency } \\
(n)\end{array}$ & $\begin{array}{c}\text { Percentage } \\
(\%)\end{array}$ & $\begin{array}{c}\text { Frequency } \\
(n)\end{array}$ & $\begin{array}{c}\text { Percentage } \\
(\%)\end{array}$ & $\begin{array}{c}\text { Frequency } \\
(n)\end{array}$ & $\begin{array}{c}\text { Percentage } \\
(\%)\end{array}$ \\
\hline Traits of the toys & 32 & 36.8 & 36 & 41.4 & 19 & 21.8 \\
Role behaviour & 17 & 19.5 & 19 & 21.8 & 51 & 58.6 \\
Emotions & 4 & 4.6 & 9 & 10.3 & 74 & 85.1 \\
\hline
\end{tabular}

Furthermore, 32 out of the advertised toys, equivalent to $36.8 \%$, are targeted at boys. These toys, unlike those targeted to girls, are more masculine and include toys such as vehicles, animals, trucks, and action figures. These advertisements also used masculine colors such as brown, black, blue, grey, and red. This portrayal induces that the colors for boy toys are referred to as bold colors. The findings further revealed that 15 of the advertised toys, amounting to $17.3 \%$, are neutral as the advertisements portray both male and female models. For example, board games, blocks, and musical instruments are the most common neutral type of toy advertisements that are identified from the data. These advertisements do not only portray both male and female models but also colors such as white, green, and yellow which do not tend to represent a specific gender.

\section{Gender Stereotype in Mattel's Toy Advertisements}

This study shows that gender stereotypes exist mostly in the traits of the toys. The traits are designed based on types of gender. As mentioned in the previous section, the boy traits suggest that boys play with action figures, animals, and transportation, while girls are depicted with feminine attributes playing with dolls, enchanted or magical animals, as well as accessories. These attributes are portrayed in toy advertisements, suggesting that girls cherish beauty while boys focus more on strength. Table 2 depicts gender representation in Mattel's toy advertisements on SNSs.

Table 2 shows that 36, equivalent to $41.3 \%$ of the advertised toys on Mattel's Facebook page, have female traits, while $36.7 \%$ have male traits. Whereas, only $21.8 \%$ of the advertised toys are neutral, having both male and female traits. Additionally, 19 of the advertised toys, amounting to $21.8 \%$, have feminine role behaviors, while only $19.5 \%$ are associated with masculine role behaviors. For instance, while girl models were shown playing with dolls or washing plates, boy models were shown playing with trucks and military-related toys. Nevertheless, a large majority of the toys, amounting to $58.6 \%$, do not have the elements of role behavior. Gender stereotypes exist in many areas such as traits, role behaviors, emotions, and occupations. The responsibility to lead and play the role in society must be fulfilled equally by both male and female individuals.

The findings further revealed that $85.1 \%$ of the advertised toys do not show specific emotions or represent male or female emotions. Only $4.6 \%$ and $10.3 \%$ of the male and female models revealed emotions. These findings indicate that gender stereotypes concerning emotions are insignificant in toy advertisements on Mattel's Facebook page. In this respect, the masculine description of emotions is not applied in the majority of toy advertisements under study. Both male and female models are portrayed as children who play and enjoy their playtimes with their friends. They are portrayed as sharing the same joy, sharing toys, and enjoying the existence of the toys they have.

\section{DISCUSSION}

The findings reported in this study have shown evidence of gender stereotypes, particularly on Mattel's toy advertisements on SNSs, as girl models dominated the advertisements. It was found that most of the advertised toys are targeted at girls. These findings concur with Kahlenberg and Hein's (2010) study which 
revealed that most toy advertisements were meant for girls. The findings also showed that color palettes associated with girls are dominant in advertisements. Some previous studies also reported similar findings (Auster \& Mansbach, 2012; Fine \& Rush, 2018). In this regard, Boe and Woods (2018) mentioned that colors also represent internalized schemas that lead to the creation of gender differences.

The advertisements also consist of more feminine than masculine traits and role behaviors. Similarly, most previous studies show that females are mostly shown in advertisements playing domestic roles such as housewives, and caregivers, while male models are portrayed as professionals (Brown, 2000; Davis \& Hines, 2020; Johnson \& Young, 2002; Owen \& Padron, 2015). Based on the assumptions of Gender Schema theory, this representation may influence children's perceptions of gender roles and behaviors in favor of girls. Some previous studies indicated that stereotypical gender representation may lead to distorted perceptions of gender roles (Carta et al., 2021; Samuelson, 2021).

The present study also indicated that while most of the advertised toys do not show specific emotions, girl models have more emotions compared to boy models. These findings concur with Owen and Padron's (2015) study which found that female models were portrayed as more emotional than male models. Similarly, Johnson and Young (2002) found that male-targeted advertisements contain more elements emphasizing action, competition, destruction, and control over others whereas female-targeted advertisements contain limited activities, expression of feelings, and nurturing behaviors.

The findings of this study indicate the need to have a more balanced portrayal of toys on Mattel's Facebook page, previous research shows that gender stereotypes occur when there is a discrepancy in the distribution of roles by both male and female individuals in a social context (Koenig \& Eagly, 2014; Samuelson, 2021). Gender stereotypes exist in many areas such as traits, role behaviors, emotions, and occupations. The responsibility to lead and play the role in society must be fulfilled equally by both male and female individuals. Most toy companies and advertising agencies tend to advertise stereotyped toys that exaggerate gender differences (Auster \& Mansbach, 2012). Perhaps, this exaggeration is meant to build brand loyalty, increase sales, and maximize profits.

\section{CONCLUSION}

This study explored gender stereotypes in toy advertisements on SNSs, specifically Mattel's official Facebook page. The findings show that girl models dominated the toy advertisements on Mattel's Facebook page. Toys such as dolls, accessories, and enchanted animals targeted to girls are more frequently posted. This discrepancy occurs because toy advertisements for girls portray more female models and feminine theme colors such as pink and purple. On the other hand, toys that are targeted at boys portray more male models and use masculine theme colors such as black, red, and blue. Society is driven by the concept that certain attributes are associated with different types of gender. Female models, for example, are often portrayed in a revealing outfit which could cause uncomfortable situations for some audiences (Azmi et al., 2017). In the context of toy advertisements, although a certain level of equality in the roles could be observed, the desired level of equality in certain traits is yet to occur. The findings show that gender stereotypes exist in toy advertisements. However, most of the advertised toys on Mattel's Facebook page do not reveal emotions.

This study concludes that it is common for companies to have a clear target audience, and thus the toys are specifically designed and created to meet the needs of the consumers. It is not surprising that toys designed for girls differ from the type of toys that are designed for boys. However, the notion of gendered toy commercials must be taken seriously. Each of the symbolic visuals is critical for the development of children. This because, based on the assumptions of Gender Schema theory, children's perceptions of gender roles could be formed based on how gender-related media messages are disseminated to them at an early age Therefore, marketers and advertisers should promote the idea of gender-free advertisements. This study contributes to a relatively under-searched area by expanding research findings and advancing our knowledge of gender stereotypes in toy advertisements on SNSs. However, the study is limited to Mattel's toy advertisements with a small sample of 87 advertisements. Thus, further research may replicate this analysis on different online advertising platforms with larger samples to provide more generalizable outcomes.

Author contributions: All authors were involved in concept, design, collection of data, interpretation, writing, and critically revising the article. All authors approve final version of the article. 
Funding: The authors received no financial support for the research and/or authorship of this article.

Declaration of interest: Authors declare no competing interest.

Data availability: Data generated or analysed during this study are available from the authors on request.

\section{REFERENCES}

Antoniadis, I. I., Saprikis, V. S., \& Karteraki, E. E. (2019). Consumers' attitudes towards advertisement in YouTube. In A. Kavoura, E. Kefallonitis, \& A. Giovanis (Eds.), Strategic innovative marketing and tourism (pp. 253-261). Springer, Cham. https://doi.org/10.1007/978-3-030-12453-3_29

Auster, C. J., \& Mansbach, C. S. (2012). The gender marketing of toys: An analysis of color and type of toy on the Disney Store website. Sex Roles, 67, 375-388. https://doi.org/10.1007/s11199-012-0177-8

Azmi, N. J., Rashid, R. A., Mohamad, B., Rahman, M. A., \& Ahmad, Z. (2017). Students athletes' perception of female models in sports advertisement. Asian Social Science 13(10), 120-123. https://doi.org/10.5539/ass.v13n10p120

Baek, Y. M. (2015). Political mobilization through social network sites: The mobilizing power of political messages received from SNS friends. Computers in Human Behavior, 44, 12-19. https://doi.org/10.1016/j.chb.2014.11.021

Bakir, A., Blodgett, J. G., \& Rose, G. M. (2008). Children's responses to gender-role stereotyped advertisements. Journal of Advertising Research, 48(2), 255-266. https://doi.org/10.2501/S002184990808029X

Bansal, M., \& Gupta, S. (2014). Impact of newspaper advertisement on consumers behavior. Global Journal of Finance and Management, 6(7), 669-679.

Beasley, B., \& Collins Standley, T. (2002). Shirts vs. skins: Clothing as an indicator of gender role stereotyping in video games. Mass Communication \& Society, 5(3), 279-293. https://doi.org/10.1207/S15327825MCS0503_3

Bem, S. L. (1981). Gender schema theory: A cognitive account of sex typing. Psychological Review, 88(4), $354-$ 364. https://doi.org/10.1037/0033-295X.88.4.354

Blakemore, J., Berenbaum, S., \& Liben, S. (2008). Gender Development. Taylor \& Francis.

Bock, A., Isermann, H., \& Knieper, T. (2011). Quantitative content analysis of the visual. In L. Pauwels \& D. Mannay (eds.), The SAGE handbook of visual research methods (pp. 265-282). Sage Publications. https://doi.org/10.4135/9781446268278.n14

Boe, J., \& Woods, R. (2018). Parents' influence on infants' gender-typed toy preferences. Sex Roles, 79, 5-6. https://doi.org/10.1007/s11199-017-0858-4

Boudreau, M., \& Watson, R. (2006). Internet advertising strategy alignment. Internet Research, 16(1), $23-37$. https://doi.org/10.1108/10662240610642523

Bovée, C. L., \& Arens, W. L. (1992). Contemporary advertising. McGraw-Hill Education.

Boyd, D. M., \& Ellison, N. B. (2007). Social network sites: Definition, history, and scholarship. Journal of Computer-Mediated Communication, 13(1), 210-230. https://doi.org/10.1111/j.1083-6101.2007.00393.x

Canevello, A. (2020). Gender schema theory. Encyclopedia of Personality and Individual Differences, 1741-1743. https://doi.org/10.1007/978-3-319-24612-3_978

Carta, A., Carraro, E., Martini, S. A., \& Perasso, G. (2021). Fifty shades of pretty and thin: Psychological research on gender stereotypes in media and advertising. In Handbook of research on translating myth and reality in women imagery across disciplines (pp. 213-232). IGI Global. https://doi.org/10.4018/978-1-7998-64585.ch011

Chan, K., \& Chan, K. (2005). Information content of television advertising in China: An update. Asian Journal of Communication, 15(1), 1-15. https://doi.org/10.1080/0129298042000329766

Chernova, V. Y., Tretyakova, O. V., \& Vlasov, A. I. (2018). Brand marketing trends in Russian social media. Media Watch, 9. https://doi.org/10.15655/mw/2018/v9i3/49478

Cohen, L., Manion, L., \& Morrison, K. (2007). Morrison, research method in education. Routledge. https://doi.org/10.4324/9780203029053

Creswell, J. W. (2003). Research design: Qualitative, quantitative, and mixed methods approaches. Sage publications.

Crowe, C. (2015). How do family background and self-esteem affect an individual's perception of gender-role portrayal in online advertising? https://digitalcommons.winthrop.edu/mcnair_sre/1/ 
Dao, V. W., Hanh Le, N. A., Cheng, M. J., \& Chen, C. D. (2014). Social media advertising value: The case of transitional economies in Southeast Asia. International Journal of Advertising, 33(2), 271-294. https://doi.org/10.2501/IJA-33-2-271-294

Davis, J. T., \& Hines, M. (2020). How large are gender differences in toy preferences? A systematic review and meta-analysis of toy preference research. Archives of Sexual Behavior, 49(2), 373-394. https://doi.org/10.1007/s10508-019-01624-7

Fine, C., \& Rush, E. (2018). Why does all the girls have to buy pink stuff? The ethics and science of the gendered toy marketing debate. Journal of Business Ethics, 149(4), 769-784. https://doi.org/10.1007/s10551-0163080-3

Friedman, G. (2017). A future for growth. Review of Radical Political Economics, 1(1), 1-11. https://doi.org/10.1177/0486613417717496

Gallaugher, J., \& Ransbotham, S. (2010). Social media and customer diablog management at Starbucks. MIS Q Executive, 9(4). https://aisel.aisnet.org/misqe/vol9/iss4/3

Gerbner, G., Gross, L., Morgan, M., \& Signorielli, N. (1994). Growing up with television: The Cultivation Perspective. In J. Bryant \& D. Zillmann (Eds.), Media effects. Erlbaum.

Harris, J., Webb, V., Sacco, S., \& Pomeranz, J. (2020). Marketing to children in supermarket: an opportunity for public policy to improve children's diet. International Journal of Environmental Research and Public Health, 17(4), 1284. https://doi.org/10.3390/ijerph17041284

Hassan, I., \& Azmi, M. N. (2019). Visual framing of Islam in online newspapers: Evidence from selected Muslimmajority nations. Humanities \& Social Sciences Reviews, 7(6), 1134-1141. https://doi.org/10.18510/hssr.2019.76162

Hassan, I., Azmi, M. N. L., \& Abdullahi, A. M. (2020). Evaluating the spread of fake news and its detection. Techniques on social networking sites. Romanian Journal of Communication and Public Relations, 22(1), 111-125. https://doi.org/10.21018/rjcpr.2020.1.289

Hassan, I., Azmi, M. N., \& Abubakar, U. I. (2017). Framing Islam in news reporting: A comparative content analysis. Asian Social Science, 13(10), 112-119. https://doi.org/10.5539/ass.v13n10p112

Hines, M. (2015). Gendered development. In: R. M. Lerner \& M. E. Lamb (Eds.), Handbook of child development and developmental science (7th ed.). Wiley. https://doi.org/10.1002/9781118963418.childpsy320

Hoy, M. G., \& Milne, G. (2010). Gender differences in privacy-related measures for young adult Facebook users. Journal of Interactive Advertising, 10(2), 28-45. https://doi.org/10.1080/15252019.2010.10722168

Hsieh, H. F., \& Shannon, S. E. (2005). Three approaches to qualitative content analysis. Qualitative Health Research, 15(9), 1277-1288. https://doi.org/10.1177/1049732305276687

Johnson, F., \& Young, K. (2002). Gendered voice in children's television advertising. Critical Studies in Media Communication,19(4), 461-480. https://doi.org/10.1080/07393180216572

Kahlenberg, S. G., \& Hein, M. M. (2010). Progression on Nickelodeon? Gender-role stereotypes in toy commercials. Sex Roles, 62(11-12), 830-847. https://doi.org/10.1007/s11199-009-9653-1

Kane, E. (2006). No way my boys are going to be like that: Parents response to children's gender nonconformity. Gender and Society, 20(2), 149-176. https://doi.org/10.1177/0891243205284276

Kim, J., \& McMillan, S. J. (2008). Evaluation of internet advertising research: A bibliometric analysis of citations from key sources. Journal of Advertising, 37(1), 99-112. https://doi.org/10.2753/JOA0091-3367370108

Knoll, J. (2016). Advertising in social media: A review of empirical evidence. International Journal of Advertising, 35(2), 266-300. https://doi.org/10.1080/02650487.2015.1021898

Koenig, A. M., \& Eagly, A. H. (2014). Evidence for the social role theory of stereotype content. Journal of Personality and Social Psychology, 107(3), 371-392. https://doi.org/10.1037/a0037215

Kotler, P. (2002). Marketing Management. Prentice-Hall.

Li, H. (2011). The interactive web: Toward a new discipline. Journal of Advertising Research, 51(1), $13-26$. https://doi.org/10.2501/JAR-51-1-013-026

Lopez-Castroman, J., Moulahi, B., Azé, J., Bringay, S., Deninotti, J., Guillaume, S., \& Baca-Garcia, E. (2020). Mining social networks to improve suicide prevention: A scoping review. Journal of Neuroscience Research, 98(4), 616-625. https://doi.org/10.1002/jnr.24404

Mangold, W. G., \& Faulds, D. J. (2009). Social media: The new hybrid element of the promotion mix. Business Horizons, 52(4), 357-366. https://doi.org/10.1016/j.bushor.2009.03.002 
Martin, C. L., \& Halverson Jr, C. F. (1981). A schematic processing model of sex typing and stereotyping in children. Child Development, 52(4), 1119-1134. https://doi.org/10.2307/1129498

Meyer, M., Adkins, V., Yuan, N., Weeks, H. M., Chang, Y. J., \& Radesky, J. (2019). Advertising in young children's apps: A content analysis. Journal of Developmental \& Behavioral Pediatrics, 40(1), 32-39. https://doi.org/10.1097/DBP.0000000000000622

Mir, I. \& Zaheer, A. (2012). Verification of Social Impact Theory claims in social media context. Journal of Internet Banking and Commerce, 17(1), 1-15. http://www.icommercecentral.com/open-access/verification-ofsocial-impact-theory-claims-in-social-media-context.php?aid=38075

Neto, F., \& Furham, A. (2005). Gender roles portrayal in children's television advertisement. International Journal of Adolescent and Youth, 12(1-2), 69-90. https://doi.org/10.1080/02673843.2005.9747944

O'Barr, W. (2015). What is advertising? Advertising \& Society Review,16(3). https://doi.org/10.1353/asr.2015.0019

Obar, J. A., \& Wildman, S. (2015). Social media definition and the governance challenge: An introduction to the special issue. Telecommunications Policy, 39(9), 745-750. https://doi.org/10.1016/j.telpol.2015.07.014

Ohajionu, U. C., \& Mathews, S. (2015). Advertising on social media and benefits to brands. Journal of Social Sciences and Humanities, 10(2), 335-351.

Owan, V. J., Ekpe, M. B., \& Eneje, S. (2020). Undergraduates' utilization of social networking media and sexual behaviours in higher education: A case study. Pedagogical Research, 5(2), 1-8. https://doi.org/10.29333/pr/7940

Owen, P. R., \& Padron, M. (2015). The language of toys: Gendered language in toy advertisements. Journal of Research on Women and Gender, 6(1), 67-80.

Rashid, R. A., Fazry A. R. M., \& Abdul Rahman, S. B. (2016). Teachers' engagement in social support process on a networking site. Journal of Nusantara Studies, 1(1), 34-45. https://doi.org/10.24200/jonus.vol1 iss1 pp3445

Rudy, R., Popova, L., \& Linz, D. (2010). The context of current content analysis of gender roles: An introduction to special issue. Sex Roles, 62(11-12), 705-720. https://doi.org/10.1007/s11199-010-9807-1

Sadek, H. (2021). Social media advertising influence on users' responses in Egypt. International Journal of Online Marketing (IJOM), 11(1), 1-13. https://doi.org/10.4018/IJOM.2021010101

Samuelson, C. (2021). Which toys are right for boys? How threat and confirmation of the gender hierarchy impact purchase intentions for stereotypical and counter stereotypical products (Doctoral dissertation). Georgia Southern University, Georgia.

Saxena, A., \& Khanna, U. (2013). Advertising on social network sites: A structural equation modelling approach. Vision, 17(1), 17-25. https://doi.org/10.1177/0972262912469560

Schimmelpfennig, C. (2019). The use of different endorser types in advertising: a content analysis of magazine $\begin{array}{llll}\text { advertisements. Journal of } & \text { Global }\end{array}$ https://doi.org/10.1080/08911762.2018.1470273

Sinha, N., \& Singh, P. (2020). Social networking sites' advertising effectiveness: a systematic insight into literature. International Journal of Indian Culture and Business Management, 20(1), 37-59. https://doi.org/10.1504/IJICBM.2020.105555

Tan, L., Ng, S. H., Omar, A., \& Karupaiah, T. (2018). What's on YouTube? A case study on food and beverage advertising in videos targeted at children on social media. Childhood Obesity, 14(5), 280-290. https://doi.org/10.1089/chi.2018.0037

Van Oosten, J. M., Vandenbosch, L., \& Peter, J. (2017). Gender roles on social networking sites: investigating reciprocal relationships between Dutch adolescents' hypermasculinity and hyperfemininity and sexy online self-presentations. Journal of Children and Media, 11(2), 147-166. https://doi.org/10.1080/17482798.2017.1304970

Walter, E., \& Gioglio, J. (2014). The power of visual storytelling: How to use visuals, videos, and social media to market your brand. Mc-Graw-Hill Education.

Weaver, D. H. (2007). Thoughts on agenda setting, framing, and priming. Journal of Communication, 57(1), 142147. https://doi.org/10.1111/j.1460-2466.2006.00333.x

Yildirim, T., \& Milla, A. (2019). A Critical Evaluation of the Effects of Advertisements Targeted to Children. In A. Al-Masri \& K. Curran (Eds.), Smart technologies and innovation for sustainable future, advances in science, technology \& innovation (pp. 21-27). Springer. https://doi.org/10.1007/978-3-030-01659-3_3 
N. J. Azmi et al.

Zimmermann, L. K. (2017). Preschoolers' perceptions of gendered toy commercials in the US. Journal of Children and Media, 11(2), 119-131. https://doi.org/10.1080/17482798.2017.1297247

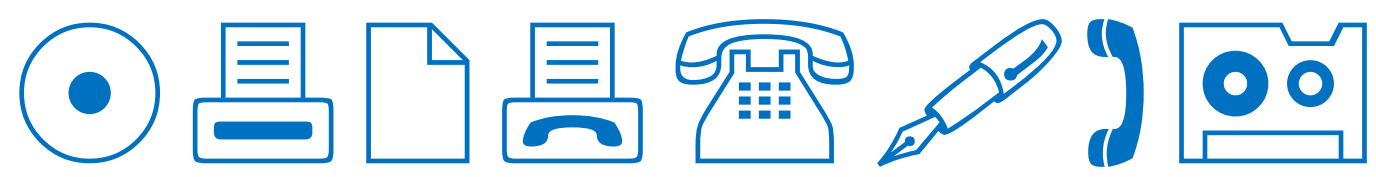

